\title{
Issues in offshore platform research - Part 1: Semi-submersibles
}

\author{
R. Sharma ${ }^{1}$, Tae-Wan Kim², O. P. Sha ${ }^{3}$, S. C. Misra ${ }^{4}$ \\ ${ }^{I}$ Department of Ocean Engineering, Indian Institute of Technology Madras, Chennai, India. \\ ${ }^{2}$ Department of Naval Architecture and Ocean Engineering, Research Institute of Marine Systems Engineering, \\ Seoul National University, Seoul, Republic of Korea. \\ ${ }^{3}$ Department of Ocean Engineering and Naval Architecture, Indian Institute of Technology Kharagpur, Kharagpur, India. \\ ${ }^{4}$ Indian Maritime University, Visakhapatnam Campus, India.
}

\begin{abstract}
Availability of economic and efficient energy resources is crucial to a nation's development. Because of their low cost and advancement in drilling and exploration technologies, oil and gas based energy systems are the most widely used energy source throughout the world. The inexpensive oil and gas based energy systems are used for everything, i.e., from transportation of goods and people to the harvesting of crops for food. As the energy demand continues to rise, there is strong need for inexpensive energy solutions. An offshore platform is a large structure that is used to house workers and machinery needed to drill wells in the ocean bed, extract oil and/or natural gas, process the produced fluids, and ship or pipe them to shore. Depending on the circumstances, the offshore platform can be fixed (to the ocean floor) or can consist of an artificial island or can float. Semi-submersibles are used for various purposes in offshore and marine engineering, e.g. crane vessels, drilling vessels, tourist vessels, production platforms and accommodation facilities, etc. The challenges of deepwater drilling have further motivated the researchers to design optimum choices for semi-submersibles for a chosen operating depth. In our series of eight papers, we discuss the design and production aspects of all the types of offshore platforms. In the present part I, we present an introduction and critical analysis of semi-submersibles.
\end{abstract}

KEY WORDS: Deepwater drilling; Semi-submersible; Mooring systems; Maneuvering characteristics.

\section{INTRODUCTION}

An offshore platform is a large structure (floating or fixed) which is used to house workers and machinery needed to drill wells in the ocean bed, extract oil and/or natural gas, process the produced fluids, and ship or pipe them to shore. Based upon the geographic location a platform cab be fixed to the ocean floor, can consist of an artificial island, or can be a float structure. The offshore platforms can be classified on the basis of operating water depths, and the two classifications are: shallow water offshore platforms and deep water offshore platforms. Also, the offshore platforms can be classified on the basis of their objective, and the two classifications are: drilling offshore platforms, storage offshore platforms and drilling/storage/offloading platforms. The shallow water offshore platforms can be of two types: fixed offshore platforms and floating offshore platforms. The classification of the offshore platforms is listed in Table 1. Till recently, the production economics ensured that most of the offshore platforms were located on the continental shelf at shallow water depths. However, because of drying resources at the shallow water depths and with advances in

Corresponding author: Tae-Wan Kim

e-mail:taewan@snu.ac.kr technology and increasing crude oil prices, drilling and production in deeper waters has become both feasible and economically viable. This has given rise to the more interest in to the deeper water platforms. In general, an offshore platform can have around 30 50 wellheads that are located on the platform and directional drilling allows reservoirs to be accessed at both different depths and at remote positions up to $10 \sim 15 \mathrm{~km}$ from the platform. The remote subsea wells are connected to the platform by flow lines and by umbilical connections and these subsea solutions consist of single wells or of a manifold centre (i.e. consisting of orbits whose behavior around the equilibrium point is not controlled by either the attraction of the stable manifold or the repulsion of the unstable manifold) for multiple wells. A semisubmersible is a special type of 'watercraft' that has much of its hull form $(70 \sim 85 \%)$ underwater. Since, for a semisubmersible the water plane is low, the semi-submersible is less affected by the waves than a normal ship. However, it needs proper and continuous ballasting to achieve desired trim and stability. Hence, semi-submersibles show far less motions in waves than mono-hull vessels, and it makes them suitable for tasks that demand very strict motion requirements. In modern engineering environment semi-submersibles are used as crane vessels, drilling vessels, production platforms and accommodation facilities. A semi-submersible offers better motion characteristics; equal resistance to wave, wind, 
and current from any direction; the ability to support a mooring system; and a large deck area. Furthermore, with the ever increasing requirements for working in deeper waters the recent semi-submersibles are often fitted with a 'Dynamic Position System (DPS)' to control the craft more efficiently. A technical analysis of semi-submersible is shown in Table 2. For exploration purposes, a semi-submersible is the design of choice for development drilling. The design of semisubmersible is a process that employs model tests and numerical simulations in the field of motions, mooring loads, wave drift forces and Dynamic Positioning (DP). The critical issues are the accurate estimation of the impact of 'green water', 'slamming' and 'Vortex Induced Motions (VIM)' on semi-submersibles. Semi-submersibles are designed for extreme wave conditions and the motions characteristics in extreme wave conditions become important. Also, wave impact loads on semi- submersible pontoons during transport in extreme weather conditions on the deck of a barge or heavy-load vessel are important parameters in design. The trials and monitoring are done with scaled and full-scale measurements on semi-submersibles. In offshore platforms it is preferred to have a mooring system for field development at any water depth. Apart from the issue of mooring system, there are other design considerations that affect the applicability of semi-submersible for deepwaters. The aim of our present paper is to present a critical introduction about semi-submersibles and our paper consist of general review, design considerations, optimization, and deign example, etc. This paper follows our previous interests in the offshore platforms, e.g. Sharma et al. (2009a, 2009b, 2009c, and $2009 \mathrm{~d})$. The present paper carries forward the ideas proposed in Sharma et al. (2009b). It provides a detailed description about the present work and outlines the future works that are currently being investigated. The remaining of this paper is organized as follows: Section 2 describes some basic types of semi-submersibles, Section 3 presents critical design and production issues for semi-submersible, Section 4 analyses a generic optimization approach, Section 5 discusses conversion issues for semi-submersibles, Section 6 presents futuristic uses of semi-submersible and Section 7 concludes the paper. Some technical details about the terms used in the present paper and design examples are given in Appendix.

\section{TYPES OF SEMI-SUBMERSIBLES}

\section{Tourist semi-submersible}

This type of semi-submersible features a surface craft that resembles a submarine. Tourist semi-submersibles compete with tourist submarines. Where tourist volumes are low, tourist semi-submersibles are preferred to tourist submarines because of the high cost of the latter. A tourist semi-submersible can place its passengers up to $10 \sim 15 \mathrm{~m}$ below water. It can be of monohull type for low number of passengers and speed, and catamaran type for high number of passengers and speed. The passengers board and descend to seats below the waterline, where viewing ports present an underwater view at $360^{\circ}$ viewing. The viewing port and $360^{\circ}$ viewing gives the illusion of riding in a sub-merged watercraft. Tourist semi-submersible can be used for under water viewing in various geographical locations, e.g. underwater excursions, and oceanic reefs. The passenger capacity varies between 20 and 175 (18 165 passengers and 2 10 crew members). The tourist semi-submersibles are equipped with underwater lighting, anchor chain, air conditioning, stereo systems, and night cruise systems. The main engine is normally a diesel engine and propulsion system may be propellers (for monohull) or $1 / 2$ water jets (for catamaran). The main structure consists of outer hulls, passenger hull, hydraulic cylinders, pilot house, engine room enclosures, and deck structure. The typical design parameters are: $L=15 \sim 27 \mathrm{~m}, B=3.5 \sim 20 \mathrm{~m}, T=1.5 \sim 12 \mathrm{~m}, D$ or height $=2 \sim 16 \mathrm{~m}$, Displacement up to 150tonnes, Service speed (cruise) $=25 \sim 40 \mathrm{knots}$, Service speed (viewing) $=1 \sim 2 k n o t s$, and classification code of BV The approximate construction cost including design cost is around US\$750,000 to 1,250,000. A typical image of a tourist semi-submersible is shown in Fig. 1, TS (2009) and TCSS (2009).

\section{Deep-sea ocean research semi-submersible}

A deep-sea ocean research semi-submersible is used for observing and exploring ocean environment at water depths up to $2250 \mathrm{~m}$. The design requirement is to form a stable platform in rough seas. Such vessels have conventional bow and stern separated and joined by a tubular cylinder like structure. The stern is built with decks, ladders, and fittings. The fittings are designed to ensure that the craft remain in use even with the sinking of the forward part of the ship. This design requirement, forces the entire craft to locate vertically downwards toward the ocean bottom and the stern portion remains above the waterline. The narrow tubular portion allows only small forces to be transmitted to the craft as large ocean swells and waves pass by. This general arrangement and the resulting structuring ensure the platform to be extremely stable. The typical design parameters are: $L=75 \sim 110 \mathrm{~m}, B=10 \sim 20 \mathrm{~m}, T=5.5 \sim 15 \mathrm{~m}, D$ or height $=7 \sim 18 \mathrm{~m}$, Backward pitching up to $90^{\circ}$, Height of front part above water $=10 \sim 20 \mathrm{~m}$, and Speed $=10 \sim 16 \mathrm{knots}$. This type of semisubmersible is not in-practice now.

\section{Military semi-submersible}

A military semi-submersible is used by defense forces. It has a small freeboard and all its propulsion machinery, fuel, and crew accommodations are located below waterline. The pilot station, cylindrical two-gun turret and a smokestack protrudes above its flat deck. The military semi-submersible cannot be strictly regarded as a semi-submersible as for such a vessel the depth does not change either with ballasting or de-ballasting. However, the configuration can be altered by ballasting the flooding tanks to form a low profile and stealth attack craft. In addition, it can contain other features like directable, extensible, and re-loadable spar for manipulation of its weapon, and a slightly buoyant naval mine to be released below its target, etc. The small waterplane area of 'small Waterplane Area Twin Hull (SWATH)' ships at the design waterline ensures a very stable vessel. 
Table 1 The list of classification of the offshore platforms.

\begin{tabular}{|c|c|c|}
\hline S. No. & Shallow water ${ }^{*}$ offshore platforms & Deepwater ${ }^{*}$ offshore platforms \\
\hline \multirow[t]{2}{*}{1.} & $\begin{array}{l}\text { A. Fixed platforms: Concrete offshore platforms, } \\
\text { steel offshore platforms, and concrete-steel } \\
\text { offshore platforms. Operating range: up to } 600 \mathrm{~m} \text {. } \\
\text { Concrete-steel offshore platforms: Normally } \\
\text { unmanned offshore platforms, and conductor } \\
\text { offshore platforms (satellite offshore platforms). } \\
\text { Operating range: up to } 500 \mathrm{~m} \text {. } \\
\text { B. Floating platforms: Compliant offshore } \\
\text { platforms and jack-up offshore platforms. } \\
\text { Operating range: } 600 \sim 1000 \mathrm{~m} \text {. }\end{array}$ & $\begin{array}{l}\text { A. Semi-submersibles: Operating range: } 1000 \sim 2250 \mathrm{~m} \text {. } \\
\text { B. Drillships: Operating range: } 2250 \mathrm{~m} \text { onwards. } \\
\text { C. Tension leg offshore platforms: Operating range: } \\
1000 \sim 2000 \mathrm{~m} \text {. } \\
\text { D. Spar offshore platforms: Operating range: } \\
1500 \sim 2500 \mathrm{~m} \text {. } \\
\text { For economic reasons both semi-submersible and drillship } \\
\text { are designed to have capacities for production and storage } \\
\text { (for semi-submersible the design capacity is low but for drill } \\
\text { ship it is high). } \\
\text { Operating range: For drilling and storage at moderately } \\
\text { deeper water (water depth }<2250 \mathrm{~m} \text { ) semi-submersible is and } \\
\text { will remain an attractive option. However, for ultra deep } \\
\text { water (water depth }>3500 \mathrm{~m} \text { ) large size drillships will } \\
\text { become the more favorable option in future. }\end{array}$ \\
\hline & \multicolumn{2}{|c|}{$\begin{array}{l}\text { Floating offshore production systems: FPSO (floating production, storage, and offloading system) offshore } \\
\text { ship, FSO (floating storage and offloading system) offshore ship, and FSU (floating storage unit) offshore ship. }\end{array}$} \\
\hline
\end{tabular}

Table 2 A technical analysis of semi-submersible.

\begin{tabular}{|c|c|c|c|c|c|c|c|c|}
\hline Type & $\begin{array}{c}\text { Deck } \\
\text { load }\end{array}$ & $\begin{array}{c}\text { Deck } \\
\text { area }\end{array}$ & $\begin{array}{c}\text { Maneuver- } \\
\text { ability }\end{array}$ & $\begin{array}{c}\text { Stability } \\
\text { (under motion) }\end{array}$ & $\begin{array}{c}\text { Storage } \\
\text { Volume }\end{array}$ & $\begin{array}{c}\text { Production } \\
\text { unit } \\
\text { installation }\end{array}$ & $\begin{array}{c}\text { Building } \\
\text { cost }\end{array}$ & $\begin{array}{c}\text { Operating } \\
\text { cost }\end{array}$ \\
\hline $\begin{array}{c}\text { Semi- } \\
\text { submersible }\end{array}$ & Low & High & Low & $\begin{array}{c}\text { High }{ }^{*} \\
\text { ('Though, actual } \\
\text { steering of it in bad } \\
\text { weather is very } \\
\text { difficult) }\end{array}$ & Low & Not possible & Low \\
Our analysis: Since for them initial investment is low, for moderately deeper water (water depth $<2250 m$ ) semi-submersible is \\
and will remain an attractive option. \\
However, for ultra deep water (water depth $>3500 m$ large size drillships will become the more favorable option in future. \\
\hline
\end{tabular}

Furthermore, since a submarine does not create waves, it can be very efficient craft for underwater operations. This concept has been used in some recent designs of watercrafts that consist of two submarines like structures underwater. The superstructure can be mounted on streamlined pylons or joined to the hulls with continuous members with sloped sides. The joining with continuous members forms stealth-like structure that is less visible on radar, and hence better suited for military applications. The typical design parameters are: $L=50 \sim 60 \mathrm{~m}$, $B=18 \sim 22 \mathrm{~m}, \quad T=4.0 \sim 5.5 \mathrm{~m}, \quad D \quad$ or height $=5.75 \sim 8.75 \mathrm{~m}$, Speed $=25 \sim 30$ knots, Propulsion system $=$ diesel electric, and displacement $=500 \sim 650$ tonnes. . Historical details can be found in Preston (2001). Two different military semi-submersibles from two different eras are shown in Fig. 2.

\section{Heavy-lift semi-submersible}

A heavy-lift semi-submersible is used to lift and transport rigs/ outsized cargo / yachts, etc. It consists of a long and low well deck between a forward pilot house and aft machinery space.
The ballast tanks are flooded to lower the well deck below the water surface. This allows oil platforms, other vessels, or other floating cargo to be moved into position for loading. Later, the ballast tanks are de-ballasted, and the well deck rises to shoulder the load. To achieve a desired balance between the cargo-loads, the ballast tanks are pumped unevenly in a pre designed pattern. A heavy-lift semisubmersible is widely used in oil industry to transport oil drilling rigs because such a vessel can carry the rigs (with a center of gravity around $27 \sim 35 \mathrm{~m}$ above the heavy lift semisubmersible's deck) from their construction site to a drilling site at roughly three to four times the speed of a selfdeploying rig. The typical design parameters for a heavy-lift semi-submersible designed to transport very large and heavy semi-submersible drilling rigs of weight $<35000$ tonnes are: $L($ overall $)=200 \sim 235 \mathrm{~m}, B=60 \sim 65 \mathrm{~m}, D=12 \sim 15 \mathrm{~m}, T$ (maximum sailing draft) $=7.5 \sim 12.5, \quad T \quad$ (maximum submerged draft $)=27.5 \sim 32.5 \mathrm{~m}$, submerged water height above deck (aft) $=15 \sim 18 m$, submerged water height above deck (forward) $=10 \sim 14 \mathrm{~m}$, Deadweight=60000 75000tonnes, Deck 
space $=45 \sim 60 \mathrm{~m} \times 160 \sim 185 \mathrm{~m}, \quad$ Deck area $=10 \sim 12.5 \mathrm{~km}^{2}$, Propulsor output $=4 \sim 5.5 \mathrm{MW}$, Number of cabins $=35 \sim 40$, Number of crew including accommodating members $=50 \sim 75$, and Facilities including workout room, sauna, and swimming facilities. A typical image of a heavy-lift semi-submersible is shown in Fig. 3, MVBM (2009).

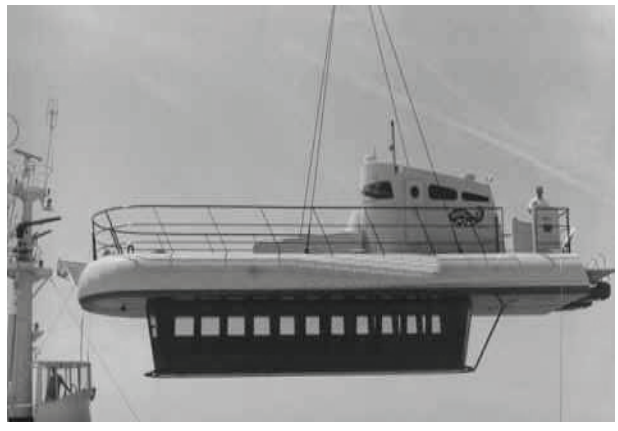

(a) A typical view of a tourist semisubmersible (mono hull).

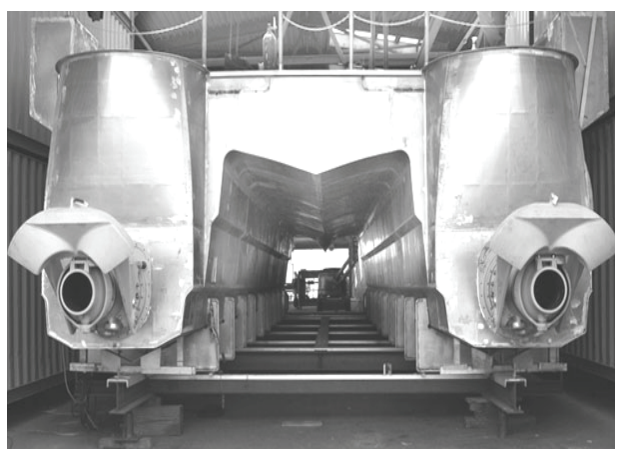

(d) Installation of port and starboard jets and engines on semi- submersible (catamaran).

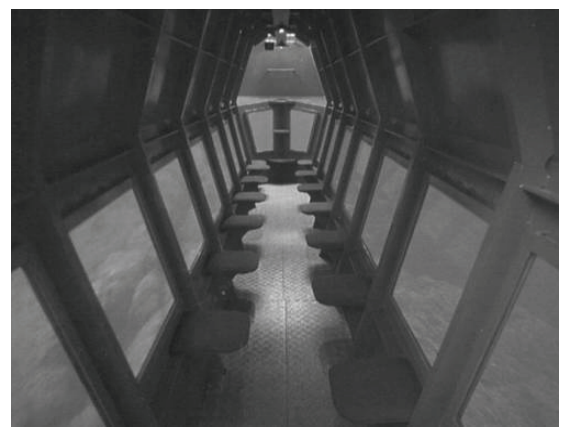

(b) A typical seating arrangement for monohull tourist semi-submersible.

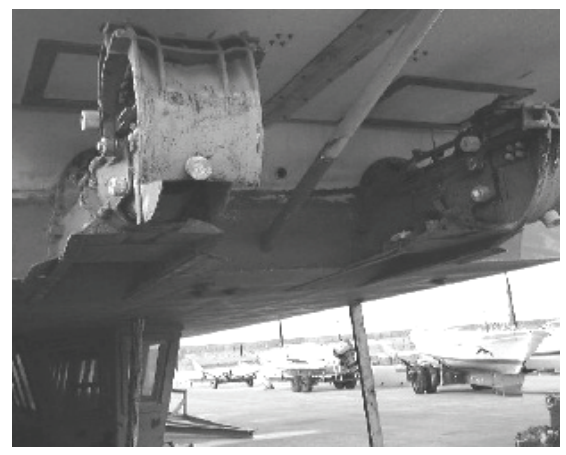

(e) Image of propulsion system of a tourist semi-submersible.

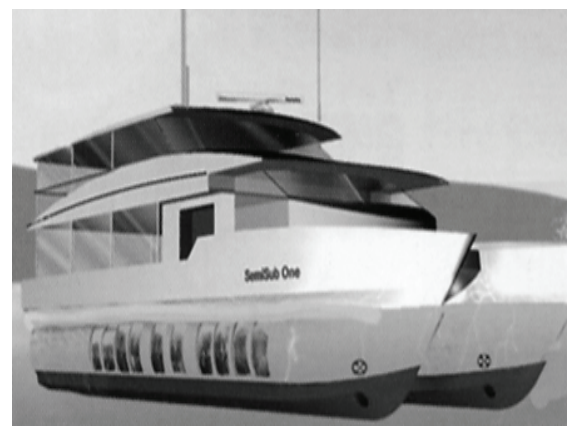

(c) An artistic image of a tourist semisubmersible (catamaran).

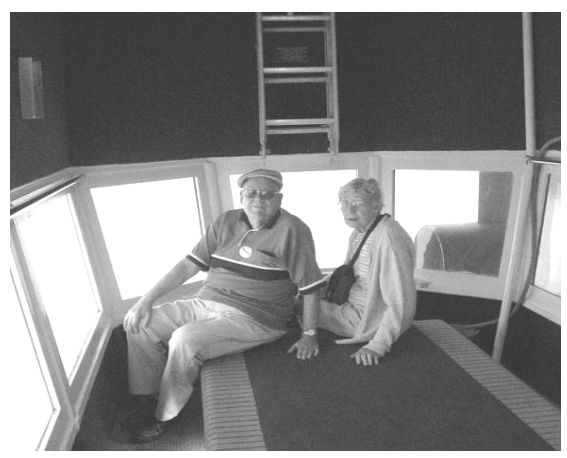

(f) A typical seating arrangement for tourist semi-submersible (catamaran).

Fig. 1 Typical images of tourist semi-submersibles.

\section{Offshore drilling semi-submersible}

An offshore drilling semi-submersible is used for drilling at deeper sea depths. Initial early designs of offshore drilling semi-submersibles were with jack-up rigs and four columns submersibles. The weight of columns and rigs is high, but without sufficient buoyancy in themselves. The extra buoyancy support is provided by pontoons (flatbottomed boat or the floats). Additionally, pontoons are used as buoyancy tanks which can be ballasted or de-ballasted. The pontoons and columns that constitute the hull are of sufficient weight proper weight distribution to cause the structure to float and also remain upright. Because of high weight of the columns, pontoons, rig and its consumables, the offshore drilling submersible is towed from one location to another at a draft mid way between the top of the pontoons and the underside of the deck. The hydrodynamic motions at this draft are very small, and this has promoted the use of semi-submersible as a stable platform for exploration drilling for offshore oil and gas. They can be towed into position by a tugboat and anchored, or moved by and kept in position by their own 'azipod' propellers with dynamic positioning system. Semi-submersibles are custom built for specific requirements for the drilling industry and the critical design issues for this type of semi-submersible are subsequently discussed in details.

\section{Crane semi-submersible}

Similar to heavy-lift semi-submersible, a crane semisubmersible is used to lift up rigs/outsized cargo/yachts and ships. A crane semi-submersible consists of lower hulls (pontoons), columns on each lower hull (pontoon) and an upper hull. At present, a crane semi-submersible is capable of lifting up to 25000tonnes, and this upper limit is increasing with new designs. A crane semi-submersible is de-ballasted to a draft where only part of the lower hull is submerged in its transit journey. However, during lifting operations, the vessel is ballasted. The ballasting appropriately submerges the lower hull and reduces the effects of waves and swells on the vessel. 


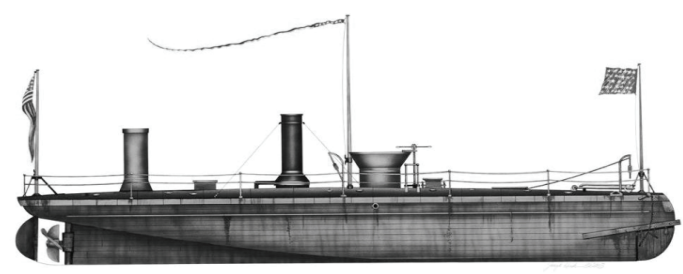

(a) An old military semi-submersible USS Spuyten Duyvil (1864).

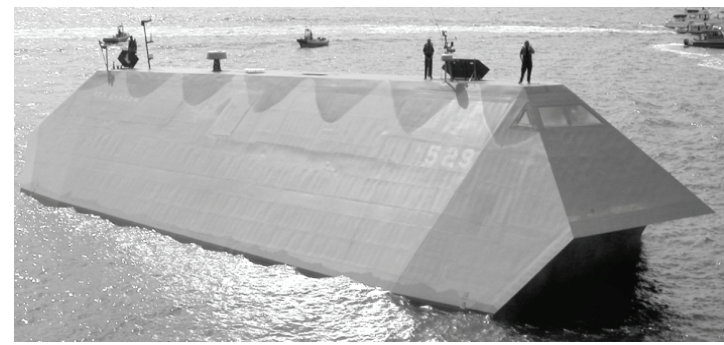

(b) A new military semi-submersible Sea Shadow (IX-529)

(1985).

Fig. 2 Military semi-submersibles from two different eras.

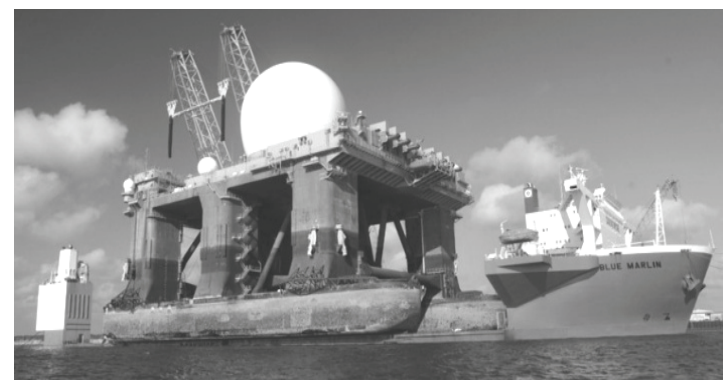

(a) A typical heavy lifting semi-submersible transporting a radar unit.

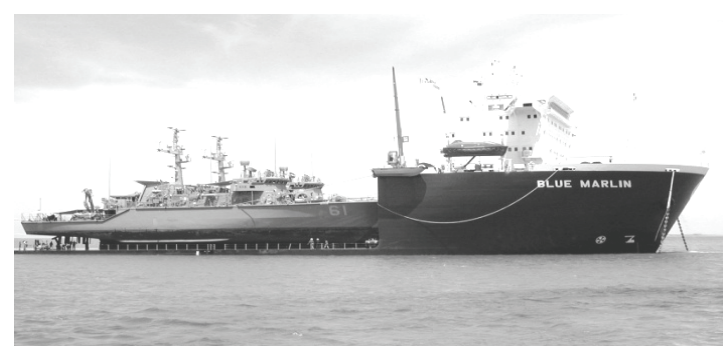

(b) A typical heavy lifting semi-submersible transporting a coastal mine hunter ship.

Fig. 3 A typical image of a heavy-lift semi-submersible.

The greater column spacing allows the crane semisubmersible to achieve higher stability and thus lift extreme high loads. A crane semi-submersible can moor the hub facilities at water depth of up to $2500 \mathrm{~m}$. The recent designs have been able to install flow line at around $2800 \mathrm{~m}$ of water depth. The typical design parameters are (for a crane design to lift up rigs/outsized cargo/ yachts and ships of weight $<4000$ tonnes, crane capacities: up to 4000tonnes, positioning system: up to class III DPS, number of propellers: up to 2 , Azimuth thruster power: up to $4000 \mathrm{~kW}$, hull: up to two floaters ( $\mathrm{draft}=10 \sim 15 \mathrm{~m}$ ) with three columns each, transit draft: $\pm 10 \sim 15 \mathrm{~m}$, and ballasting down draft: $20 \sim 30 \mathrm{~m}): L$ (overall) $=135 \sim 165 \mathrm{~m}, B=75 \sim 95 \mathrm{~m}, B \quad$ (including laying system) $=105 \sim 130 \mathrm{~m}, D$ (to working deck) $=35 \sim 45 \mathrm{~m}$, Height (from laying tower to working deck) $=90 \sim 110 \mathrm{~m}$, Maximum draft $=25 \sim 35 \mathrm{~m}$, Lightship weight $=37500 \sim 60000$ tonnes, and Maximum displacement $=90000 \sim 120000$ tonnes. A typical image of a crane semi-submersible is shown in Fig. 4, CSSDCVB (2009).

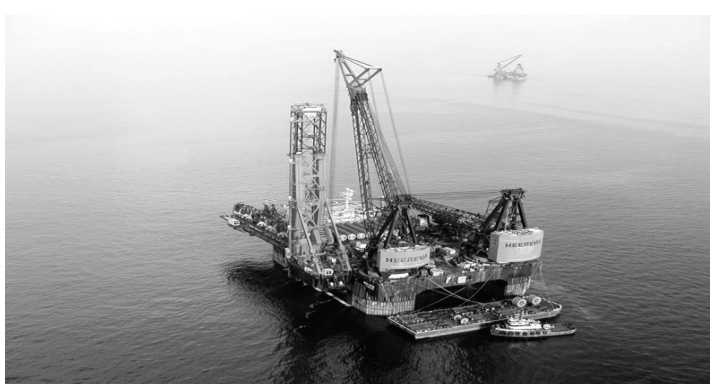

(a) A typical crane semi-submersible.

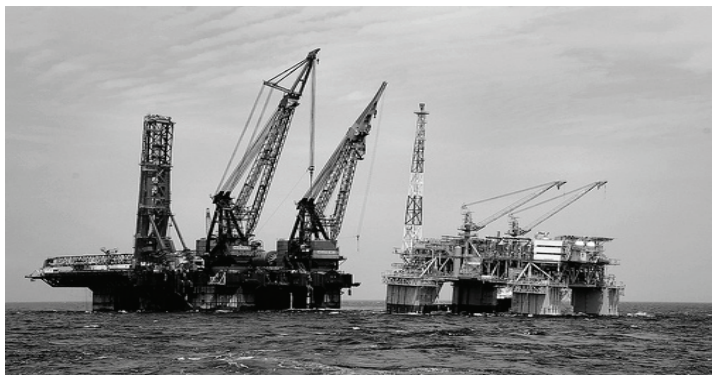

(b) A typical crane semi-submersible installing a hub facility unit.

Fig. 4 A typical image of a crane semi-submersible.

\section{Floating dry dock semi-submersible}

A floating dry dock semi-submersible is used to repair and maintain ships. The design of a floating dry dock semisubmersible is simple, and consists of either pontoon or barge for dry docking ships.

Furthermore, it possesses floodable buoyancy chambers and a "U or Open Box" shaped cross-section. The box walls provide stability to the dry dock when the pontoon/barge is below the water level. On ballasting the buoyancy chambers, the dry dock sinks to the required draft and allows the vessel to be moved on to the pontoon/barge. The dry dock is raised and the deck is cleared of water by de-ballasting the buoyancy chambers, thus allowing the underside of the hull to be accessible for repair and maintenance.

The basic advantage of floating dry dock semisubmersible is that it can be moved from one location to another throughout the world and also it has a good resale value. The typical design parameters are (for a barge design): $L=90 \sim 110 \mathrm{~m}, B=27 \sim 35 \mathrm{~m}$, and Height $=25 \sim 32 \mathrm{~m}$. A typical floating dry dock semi-submersible is shown in Fig. 5, HMB (2009). 


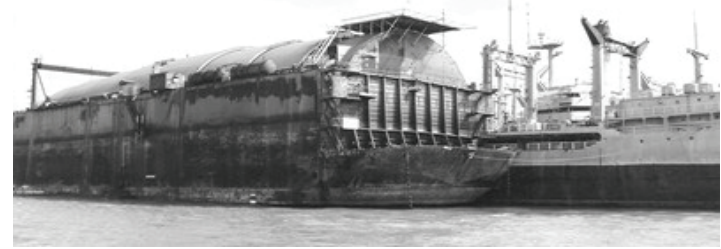

(a) A typical floating dry dock semi-submersible.

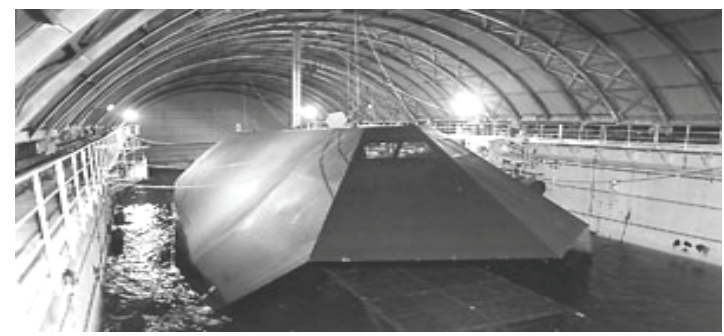

(b) A typical floating dry dock semi-submersible admitting a military semi-submersible for repair.

Fig. 5 A typical image of a floating dry dock semi-submersible.

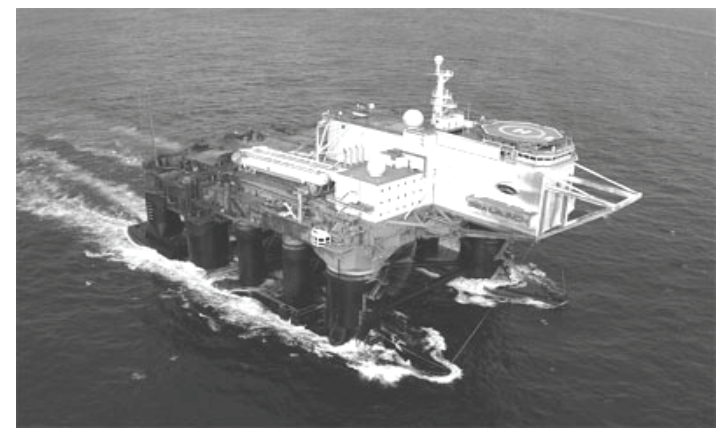

(a) A typical launching platform semi-submersible.

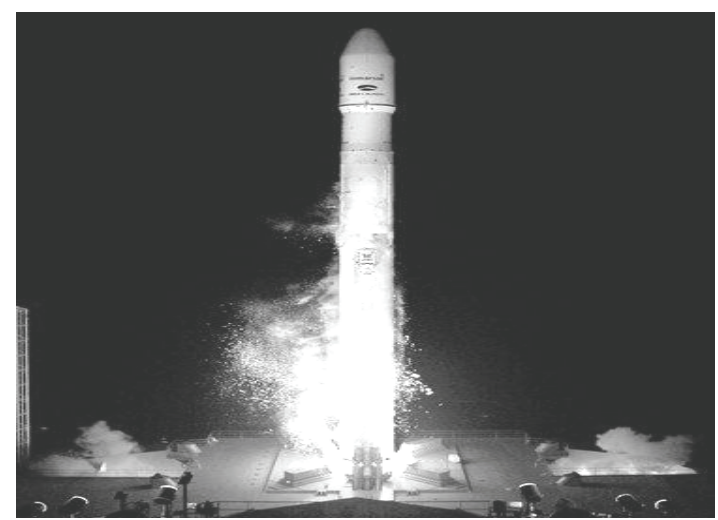

(b) A typical launching platform semi-submersible under the operation of a rocket launch.

Fig. 6 A typical image of a launching platform semisubmersible.

\section{Launching platform semi-submersible}

A launching platform semi-submersible is used to provide a launching pad for rocket launches. This is a self- propelled semi-submersible, which is normally converted from a drilling rig and rebuilt as a mobile spacecraft launch platform. During transit operations, the rockets are stored in a large, weather controlled hangar.

They are then rolled out and erected again prior to fueling and launch. The typical design parameters are (for expendable carrier rocket launching operated by sea launch, e.g. Zenit-3SL): $L=120 \sim 145 \mathrm{~m}, B=55 \sim 75 \mathrm{~m}$, empty draft displacement $=275000 \sim 40000$ tonnes, submerged draft displacement $=45000 \sim 60000$ tonnes, accommodation for 60 75 crew members and system personnel, and installed facilities including living, dining, medical and recreation facilities. A typical image of a launching platform semisubmersible is shown in Fig. 6, KSC (2009).

\section{Smuggling semi-submersible}

A smuggling semi-submersible is used to smuggle illegal materials from one coast to another. These self-propelled semi-submersibles, because of very low freeboard, low profile and fiberglass construction, are nearly undetectable by radar, sonar, and infrared systems. Therefore, such vessels are an attractive choice for illegal transportation of banned substances. Sub-marine has a high cost of construction, and that makes choice of semi-submersible for illegal transportation even better. The typical design parameters are: $L=25 \sim 45 \mathrm{~m}, \quad B=6 \sim 9 \mathrm{~m}, \quad$ Draught $=4.5 \sim 7.5 \mathrm{~m}$, Propulsion $=650 \sim 950 \mathrm{hp}$, Speed $($ surface $)=12 \sim 18 \mathrm{knots}$, Speed (submerged) $=5 \sim 8 \mathrm{knots}$, Operational range $=15000 \sim 25000 \mathrm{~km}$, Capacity $=600 \sim 850$ tonnes, $\quad$ Complimentary capacity= 2/4persons. A typical image of a smuggling semi-submersible is shown in Fig. 7, NSS (2009).

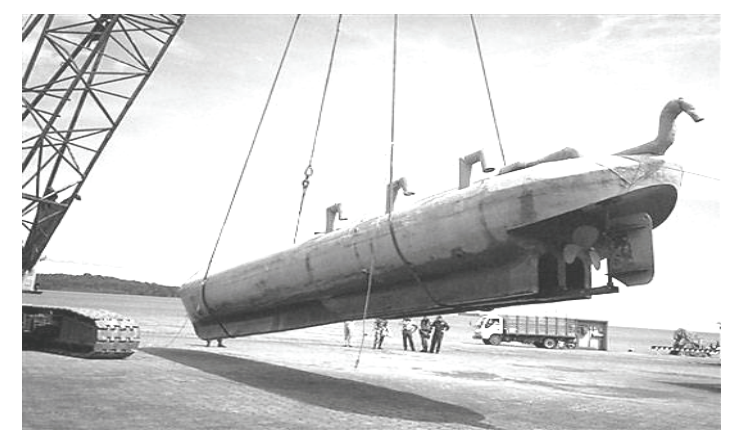

(a) A typical smuggling semi-submersible.

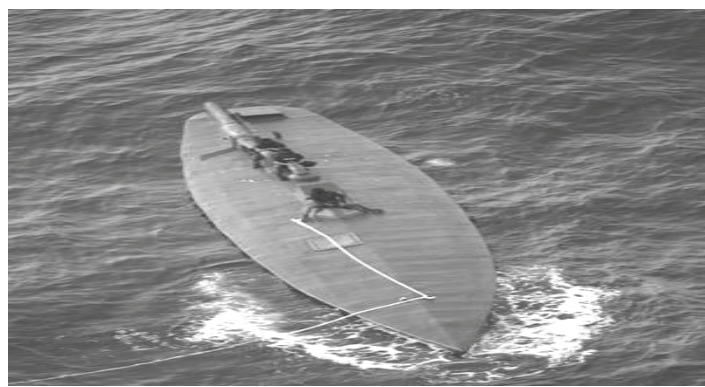

(b) A typical smuggling semi-submersible under the operation of capture.

Fig. 7 A typical image of a smuggling semi-submersible. 


\section{CRITICAL DESIGN AND PRODUCTION ISSUES FOR SEMI-SUBMERSIBLES}

A proper balanced design is arrived via an integrated approach. In the integrated approach, the design parameters (e.g. material handling equipments, deck space, motion, stability, operational characteristics, and flotation and safety, ABS (2001), API(1996), API (2003), and DNV (1996)) are optimized to get appropriate main particulars. An integrated approach for the design process of the ultra deepwater drilling units is shown in Fig. 8.

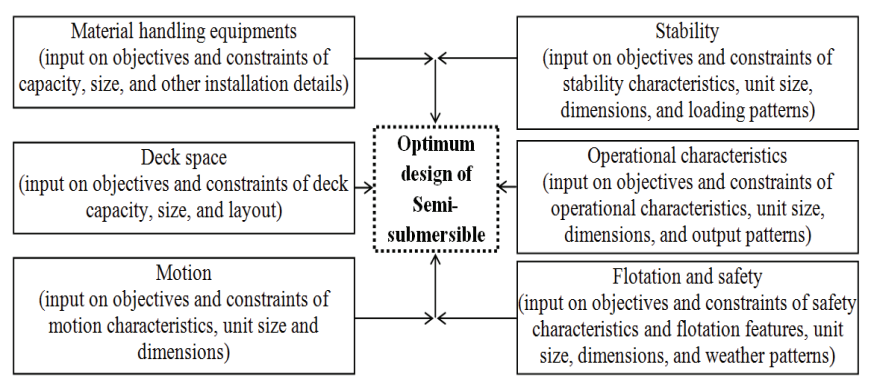

Fig. 8 Design process for the ultra deepwater drilling units.

The critical design issues that affect the performance of a semi-submersible are: vessel geometry, motions, capacity (variable drilling load and total variable load), construction (system and production), stability and safety.

Vessel geometry: From simple structural mechanics, the simple and cost-effective semi-submersible forms are shown in Fig. 9. The comparative advantages and disadvantages of the triangle and rectangle based semi-submersibles are listed in Fig. 9.

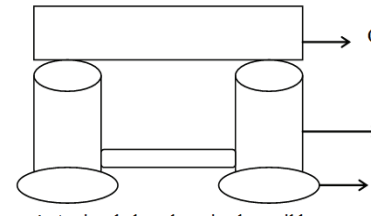

al. A triangle based semi-submersible

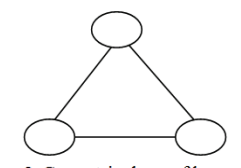

a2. Geometric sh ape of base

Advantages.

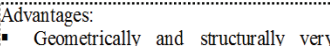

Geometrically and structurally very;
stable with minimum steel consumption: stable with minimum
and hence less weight.

imitation:

- Low deck space and transit speed.

Fig. 9 The simple and cost-effective semi-submersible forms.

The optimal design of the form configurations depend upon the following parameters,

Deck load: The desired deck load is not constant and its variation at operating draft affects the design of supply logistics. Since, deepwater platforms are normally far from the land, supply is a critical issue. In this regard, a design is preferred that can store more consumables.

Load capacity: The speed of the fully laden unit depends upon the load capacity at transit draft. The smaller pontoons may remain submerged during transit resulting in low transit speed. Though, the bigger pontoons may remain partially submerged but since their steel weight, cost, and stationkeeping forces are large they are not preferred. Furthermore, the variable load capacity at operating draft decreases as pontoon size increases. Hence, the optimum size of the pontoons is important. The larger pontoons have higher cost, unfavorable motion characteristics (bigger stability columns required to restore operating variable load reduce the natural heave period), and higher power requirements of the dynamic positioning system. The smaller pontoons also allow only short and light rig which cannot de-ballast with a useful load on board.

Environment: Wave heights, wind speed and sea currents determine the operating sea environment. These factors determine the height of the columns and the air gap between operating water level and the underside of the upper operating deck. In the harsh maritime environment, the height of the support columns should be sufficiently increased to ensure that, at survival draft, there is no wave impact on the underside of the operating deck. In severe weather this pushes the column height to a greater value than what would be expected from design considerations for a rig operating in moderate weather. Compared to high column the low column offers a larger variable load, with all other parameters being equal. In this regard, an optimum design which optimizes column size and overall rig size to provide the desired variable load and motion characteristics within the bounded constraints of economics is preferred.

The final hull design choice is made after a complete structural and hydrodynamic analysis. Initial configuration out of triangular or rectangular is selected primarily by the design agency. The ring pontoons are topped with triangular or rectangular columns. The topside deck is supported by the columns with the corners of the topside deck placed at the geographical centers of column tops. The configuration can be further extended with the help of equipments set on a triangular deck that is supported by three/four columns with a water-entrapment plate at the keel. Similarly, other extension of the original configurations can be devised to further provide additional facilities, e.g. control and chemical injection systems for subsea wells, power generation systems, multi-phase pumping systems, etc. The design requirements of a semi-submersible consist of owner's and shipbuilding yard's requirements. The requirements of the owner are related to the operational aspects, e.g. environmental conditions (wind, wave and current) for operations and survival, variable drilling load, total variable load in transit, limitations of motion behavior (e.g. heave/pitch/roll and sea state for operating conditions), safety, stability, equipment specifications, conversion possibilities, and dismantling cost. The requirements of the shipbuilding yard are related to the construction, e.g. optimum utilization of shipyard's fabrication facilities from metal cutting to panel formation to final assembling, maximum construction width due to the 
building block facilities or waterway/channel/river restrictions. Once the requirements are specified to establish the desired set of main dimensions to fulfill the design criteria, an optimization approach is used. The optimization approach has many advantages, e.g. it enables computation of a detailed parametric study to determine the influence and relationships amongst design parameters, and an accurate design is obtained which has little modification requirements in its life cycle.

A semi-submersible design is an iterative process. A preliminary design is selected first and then it is modified in an iterative process to meet the requirements, satisfy the constraints, achieve performance levels, and minimize the investment. Since, semi-submersible is a hydrodynamic floating structure that operates in a rough and heavy sea weather, its design requires technological and scientific skills from structural mechanics and hydrodynamics. The semisubmersible is subjected to the severe environmental loads in high sea state. The design sea state can go up to 'Sea Level 3'. The ocean data for the sea/ocean site is needed for wave height, period, wind speed and current speed for both the operational and survival design condition. Normally, the operational and survival design storms are chosen to be 10 year and 100 year storm conditions respectively for the design location. The shape and height coefficients can be taken from codes of classification societies or research studies, and then applied to the constant topside shapes, the final exposed column shapes (with zero shielding) and the final component elevations once the final freeboard is calculated. The wind, current and mean wave drift are applied concurrently in the bow, beam and quartering directions so that they result in maximum environmental loads for operational and survival conditions.

The loading pattern for semi-submersible is both local and global. The structural analysis is normally performed with 3D finite element based analytical tools to determine the deflections, moments, and stresses acting on the topside, columns, and hull pontoon. The analysis conditions are: structure floating at a constant draft and with a static wave with the crest of the wave acting on two of the columns opposite from each other. Normally, this static wave with the crest of the wave acting on two of the columns opposite from each other produces maximum moments, stresses, and deflections. Then, the weights of the hull, topside, ballast tanks (filled with water), and nodes are added, along with the buoyancy acting on the bottom of the pontoon. To efficient model mooring lines, springs are added to the joint of the columns and pontoon. The inclusion of wind, wave, and current forces in structural analysis produces a dynamic problem. And, dynamic fluid structural interaction produces the reaction forces for the springs in the ' $x$ ' and ' $y$ ' directions. In general it is ensured the weights of all of the components are of equal and opposite force to the buoyancy resulting in zero net global displacement in the ' $z$ ' direction. The stresses, for both wave cases, that are created from the pressures, weights, and buoyancy need to be compared to classification society guidelines. In general, the stresses for the topside and pontoon are on the higher side while the stresses in the columns are on the lower side.
The weights for columns, pontoons and nodes are computed with approximate formulas. It is a general practice to add an additional $47.5 \sim 65.0 \%$ of the weight of columns, pontoons and nodes for marine systems, brackets, paint, and design allowances. The hull buoyancy is simply the weight of the water displaced by the pontoons, nodes and the part of the columns that are submerged either during float-on, float-off, operational or survival conditions. The down flooding angles and area ratios for intact stability need to be checked as per classification society guidelines. For damaged stability calculations, one/two/three consecutive tanks are flooded all the way around semi-submersible. The distance between down flooding angle and the first righting arm/heeling arm intercept under the worst damaged case scenario need to be checked with classification society guidelines. Normally, it should be higher $\left(\geq 5^{\circ}, \leq 10^{\circ}\right)$ than the classification society guidelines. The number of tanks that are floodable to reach operational and survival drafts as well as to offset a permanent topside center of gravity that is as far from the geographical center of gravity need to be determined.

The heave/pitch/roll motion can be determined with either experimental investigations on similar scaled models, or CFD simulations. The periods are determined using closed-form equations. Normally, the heave/pitch/roll period are around 16.25 31.25 seconds for normal semi-submersible used in-practice. The heave/pitch/roll response can be found using response amplitude operators (computed from a hull of similar dimensions) for the degree headings between 0 to 90 . Normally, the maximum heave response is found to be from around $20 \sim 25^{\circ}$ heading and is $\pm 2.250 m \sim \pm 2.875 m$ and $\pm 3.25 \mathrm{~m} \sim 4.625 \mathrm{~m}$ for the operating 10 year and survival 100 year storm conditions respectively. Similarly, the maximum pitch/roll response is found to be from around the $0 \sim 3^{\circ}$ heading and is $\pm 1.75 \sim \pm 3.125^{\circ}$ and $\pm 3.75 \sim \pm 5.25^{\circ}$ for the operating 10 year and the survival 100 year storm conditions respectively.

In ultra deepwater, for a rig it is easy to use a mooring system rather than dynamic positioning. At present, practical considerations of hydrodynamic forces, rules out any economically viable drilling rig to carry a self-deploying system in high water depths $(\geq 2250 \mathrm{~m})$.

Currently, some research is being done to design a mooring system which can be 'pre-laid' or 'pre-deployed', e.g., system with suction pile anchors. In the system with suction pile anchors a rig is brought on to the location, and then the anchor wires of rig are connected to this 'pre-laid' or 'pre-deployed' system. Since, the amount of wire connected from the rig is limited, it is critically important that the wire line winch is a traction winch and storage reel for which linepull is independent of the amount of wire. Another additional advantage of a system with suction pile anchors is that it can be supported by thruster assistance units if desired.

The mooring system design for the semi-submersible is driven by simulation. The inputs are environmental and mooring line component data. The number of legs in the mooring system can be $12 / 16, \cdots, 4 n$, where $n=3,4, \cdots$.

The materials used are chain, polyester, and spiral wire components in both taut-leg and semi-taut leg mooring system designs. The mooring lines at both the fairleads and 
anchors are composed of chain to account for an increase of stresses at the fairleads and to fit chain jacks, as well as to accommodate the situation where the mooring lines may lie on the ocean floor to avoid sediment transportation into the polyester or wire components. Normally, wire is used as the middle component because in middle position it performs well in both taut and semi-taut designs, and provides the required in-water weight for the restoring force of the semitaut system. However, it adds a significantly larger downward force on the hull. The other choice is to use polyester middle component, which can also be adapted to work well in both taut and semi-taut leg mooring systems. Although, polyester provides required stretch for the restoring force in the taut-leg configuration, it does not provide sufficient in-water weight to support an adequate restoring force in the semi-taut design. Mooring system operates in a highly dynamic environment. A dynamic analysis of the mooring system is performed with concurrent environmental forces applied in the direction of each mooring line to compute the worst case intact and damaged conditions. The results of these analyses are checked against the mooring guidelines prescribed by the classification society. In general, a polyester line suits a taut-leg system, and a wire line suits a semi-taut system. The diameter of all steel components of the mooring line is increased by $0.04 \sim 0.06 \mathrm{~mm}$ per design year for corrosion. The final design choice is selected by an optimization process that employs mooring objectives, society regulations, and cost. For the general designs studied by our design team the mooring system consists of taut system with studless chain at the anchor, polyester rope in the middle component and studless chain at the fairlead. For normal designs, the anchors are 9 13tonnes vertically loaded drag embedment anchors. The subsea blowout preventer (BOP) systems are large in size, heavy in weight, and expensive in cost. The BOP systems are stored in the moonpool area. Normally, conventional rigs have adequate space in the moonpool area to run and retrieve BOP stacks, Christmas trees and flow-lines etc. However, the moonpool area of the rigs does not have enough space to accommodate a conventional surface BOP configuration. In conventional rigs, the air gap is around $6 \sim 8 m$ and distance between the diverter housing and the underside of the rig is around $8 \sim 10 \mathrm{~m}$. This restricts the conventional surface stacking option. To avoid the storage in the moonpool area, the option of storing close to the main deck is chosen as it offers an easy location for maintenance also. Additionally, from design point of view it allows an extended rail system for coordinating the movement of BOP and subsea trees into and out of the running elevator integrated to the moonpool access. In this rail driven system BOP is skidded directly onto the BOP elevator that lowers it to clear the underside of the substructure beams. Also, the elevator runs the BOP to the starboard side of the moonpool and parks it before deployment. Tree staging operations also are handled on the port aft side of the moonpool. Also, this integrated system allows for the reduction in the number of wires, and ropes.

The BOP system stored close to the main deck is called the 'near surface BOP'. The near surface BOP is operated below the splash zone and away from the influence of currents. This concept utilizes a conventional telescopic joint to protect the rig from potential riser recoil in the event of a riser failure or emergency disconnection. The additional advantage of near surface BOP is that it can be used to extend the range of the drilling rig to deeper waters (up to $2250 \mathrm{~m}$ ) with a smaller bore riser. The riser diameter affects the deep water range, e.g. riser of $0.50 \mathrm{~m}$ diameter has a water depth range of around $1750 \mathrm{~m}$, and risers of $0.34 \mathrm{~m}$ diameter can have a water depth range of around $2250 \mathrm{~m}$. The other benefits of near surface BOP are: improved well control, no modifications required to the mud system for extension to deeper waters, suitability with existing choke and kill system, lower requirements for mud volume, lower riser running times, low anchor handling time, fully redundant controls , and less waste disposal. Furthermore, a lower diameter of riser reduces the mud volume, e.g. riser of $50 \mathrm{~cm}$ diameter requires about $190 \mathrm{~m}^{3}$ of mud and riser of $34 \mathrm{~cm}$ diameter requires $120 \mathrm{~m}^{3}$ of mud. The reduced volume of mud allows the rig to operate in deeper waters than their original design capability. Also, a lower diameter riser with near surface BOP allows the use of existing surface equipments, e.g. conventional telescopic joint, flex-joint, tension ring and drape hose gooseneck connections. The BOP is run down to a predetermined depth. And, depending upon water currents, the BOP can be arranged between two joints of riser, e.g. about $50 \mathrm{~m}$ below the surface. If there is a problem with the BOP then it can be recovered to the transporter in a shorter duration (2 4hours). If the storage is at the surface then it will need to be disconnected from the well before any maintenance or repair work can be carried out for safety reasons if there is any rig movement. The rig's conventional drilling riser can be used from the diverter to the near-surface stack.

Though, near-surface BOP occupies a higher space, it is still better than the conventional surface BOP because the telescopic joint is much larger for near surface BOP. The near surface BOP is installed outside the critical zone and is close enough to the surface so that recovery for repair takes a short time in deep and ultra deep water depths. The near surface BOP is efficiently sized to allow for the stresses of $60 \sim 80 \mathrm{MPa}$ during operation. Its configuration consists of three rams and one annular, and it is equipped with redundant conventional hydraulic controls and ROV intervention capability. The structure of near surface BOP consists: a conventional telescopic joint, various strings of conventional drilling riser, computer controlled riser adapter, annular preventer, single ram preventer, choke and kill equipment, dual ram preventer, adapter spool, wellhead connector, riser mandrel, upper/lower stress joint, casing for riser, frame work, control equipment, computer control system and a device for disconnection.

The drill string needs to be hung from the wellhead. For near surface BOP this requires an altered configuration. In the altered configuration, a special device (special subsea isolation and disconnect device (SSIDD)) is used, and it is installed on the wellhead to hang the drill string and to shear the drill pipe. The SSIDD allows safe and quick removal of the rig from the well. Normally, the SSIDD consists of two to four $30 \sim 38 \mathrm{~cm}$ diameter $(60 \sim 70 \mathrm{MPa})$ rams, valves, and 
computer controlled valve arrangement system. The aim of computer controlled valve management system is to allow an efficient monitoring of well closure and/or control before reopening. The SSIDD has MUX pod for primary control, acoustic digital spread spectrum controls for secondary control and it is supported with ROV intervention capabilities. In the integrated system the SSIDD consists of: casing riser, stress joint, riser connector, riser mandrel, shear rams, pipe (and/or shear) rams, influx isolation equipment, wellhead connector, frame work, and computer control equipment. At present, the riser tensioning capacity is around 400 500 tonnes which is less than the desired tensioning capacity of around 500 625tonnes in deeper waters. This demands an additional strengthening of tensioning system for deeper waters. Offshore structures operate under heavy loads. The combined weight of large-bore choke and kill lines, boost and dual-density lines, and hydraulic supply lines puts a high force on the tensioning system. The tensioning losses are high because units are assembled with joints, have bends, and operate with multiple connections. Furthermore, losses are accentuated because of friction, and lead angles. Normally, for an efficient design tensioning losses are assumed to be between $20 \%$ (lower side) to $22.5 \%$ (higher side). In practice, two types of tensioning systems are popular. And, they are: wire-line tensioner and hydraulic in-line tensioner. The hydraulic in-line tensioner offers higher efficiency but its use makes the moonpool area dirty with sticky fluids and that needs periodic cleaning. The wire-line tensioner does not offer high efficiency but its use keeps the moonpool area clean. The running times for casing and/or high pressure riser without auxiliary lines is low as compared to the conventional drilling riser. Hence, near surface BOP coupled with low diameter riser, strengthened tensioning system, and SSIDD offers an economic and highly efficient choice for the semi-submersibles.

\section{GENERIC OPTIMIZATION APPROACH}

Now, we describe a generic optimization approach. An optimization approach needs clearly defined parameters: free variables, technical design parameters, constraints and objective function. In computational implementation free variables are changed during the computation of the optimum solution while the parameters have fixed values defined at the input stage. The constrained parameters are the requirements that need to be fulfilled, and the objective function needs to be optimized. The objective is user selected and it can be linear, non-linear and stochastic. Because of many possibilities in the very definition of objective function it is desired that a powerful optimization technique is adopted. Some examples are linear programming technique (for linear objective function and constraints), gradient minimization technique (for non-linear objective function and linear constraints), sequential quadratic programming (SQP) technique (for non-linear objective function (for linear objective function and constraints)) and evolutionary programming technique (for stochastic objective functions and constraints). The schematic diagram of generic optimization approach is shown in Fig. 10. In Fig. 10, the main program reads the parameters values from the input set and runs the optimization process. The iterative optimization process computes the optimum values of free variables $\left(F^{*}\left(S_{f v}\right)\right)$ via iteration. The process is initialized with some starting values (initial guess $S_{f v_{0}}$ ), and then these initial values are entered in the computing zone where constraints and objective functions are checked and satisfied. The check and satisfaction of the constraints and objective functions lead to modification in the set values of $S_{f v}$. The modified set values $\left(S_{f v}^{*}\right)$ are used again and the process is continued till all the constraints and objective functions are satisfied, and the optimum $F^{*}\left(S_{f v}\right)$ is computed.

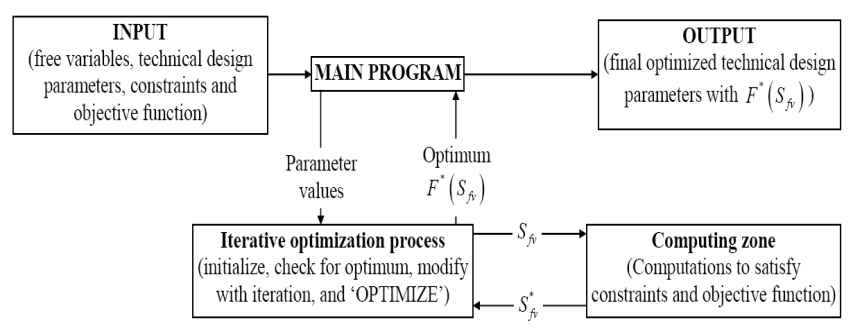

Fig. 10 The schematic diagram of generic optimization approach.

The definition of free variables depend upon the chosen primary structural configuration, e.g. 3 column semisubmersible or 4 column semi-submersible, or $n$-column semi-submersible where $n=3,4,6,8$, etc. Once a configuration is chosen then other free variable are chosen. In general nine free variables are enough, e.g. for upper deck: width and length; for columns: width, height and spacing; for floaters: width, height and length; and for column additions: size of heave plates (if designed with water-entrapment plates at the keel).

The technical design parameters consist of two categories: owner related technical design parameters (e.g. SA - sea state: environmental conditions for operations and survival, VDL: variable drilling load, TVLiT: total variable load in transit, HM: heave motion, PM: pitch motion, RM: roll motion, SL: safety level, IS: intact stability, DS: damaged stability, ES: equipment specifications, CP: conversion possibilities, and DC: dismantling cost) and shipbuilding yard related technical design parameters (e.g. CSA: cross sectional size of the deck box, HDB: height of deck box, NB: number of bracings, SBC: size of bracings, CSHP: cross sectional size of heave plate). The air gap requirements are determined from simulated results of experimental tests that are conducted on similar scaled models.

Again, the constraints are categorized: MSL $\sim$ maximum stability level, MEC - maximum operating conditions, MTVLiTs - total variable load in transit, and MRFB minimum required freeboard.

MSL-maximum stability level: A semi-submersible is classified by a professional agency, and within classification 
society rules and regulations the design aim is to achieve maximum stability levels. In general the semi-submersible has a significant buoyant upper hull structure and this feature improves IS. For damaged condition there is a restricted limit of the heeling angle and because of that the amount of water that can accumulate is limited. However, a small amount of water endanger more with free surface effects, and to achieve better damaged stability levels columns are strengthened with double hull, etc. In this configuration the vessel's restoring moment counteract the inflow of water. A linear or non-linear approximation relationship between restoring moment, displacement, GM value and angle can be used, e.g. linear approximations are fairly accurate up to $15 \sim 17.5^{\circ}$, and nonlinear relationship is needed only for higher angles (17.5 30). In both linear and non-linear relationships GM value is important.

MHM-minimum heave motion, MPM-minimum pitch motion and MRM-minimum roll motion: The motion characteristics affect the workability conditions and therefore it is desired that they are minimum under maximum drilling and operating conditions. The minimum HM/PM/RM are determined with specifying allowable drill and operation compensator limit. The HM/PM/RM depend upon natural periods and submergence of floaters. There exist various formulations that link the values. In the optimization process a natural period is selected first and then second/third/fourth hump responses are computed. An optimum value is computed with assuming second/third/fourth hump responses as constraints. A motion based analysis ensures that workable conditions are determined within a given set of environmental conditions.

MRFB-minimum required freeboard: Minimum freeboard is determined at transit draft. The floater size determines total variable load and freeboard in the transit condition. The freeboard is a flexible criterion and it is both a requirement and constraint. It is a requirement because freeboard needs to be positive and it acts as a margin for weight increase during construction. It is a constraint because the owner demands a minimum freeboard as higher freeboard means higher material consumption and cost. These conflicting requirements are settled using optimization techniques, and an optimally selected freeboard and total variable load determine efficient size of floaters and displacement of the vessel.

Production related constraints (PRS): Flat/single curved panels have a low cost of production. Hence, from cost point of view it is desired that the semi-submersible be designed with flat/single curved panels. This also adds some constraints, and they are:

- Length of floater $\geq$ upper hull length.

- Width of floater $\geq$ column width.

- Total width of vessel $\leq$ width of building dock/repair dock of the shipbuilding yard.

Objective function: The central idea is to optimize the overall performance of the semi-submersible. In general the performance definition is owner driven meaning that total investment cost (to cover total design cost, construction cost, installation cost, operation and maintenance cost and dismantling cost) is minimized. The design cost is around
4 7.5\% (i.e. low for designs already in practice and high for new and innovative designs) of the construction cost. The construction cost consists of various sub-costs like drilling cost (material cost $=27.5 \sim 32.5 \%$, labor $\cos t=2 \sim 3 \%$ ), structure cost (material cost $=4 \sim 6 \%$, labor cost $=7 \sim 8 \%$ ), machinery cost (material cost $=13 \sim 17 \%$, labor cost $=2 \sim 3 \%$ ), hull outfitting cost (material cost $=8 \sim 11 \%$, labor cost $=1.5 \sim 3.5 \%$ ), electrical machinery and fitting cost (material cost $=5.5 \sim 7 \%$, labor cost $=2 \sim 4.5 \%$ ), painting cost (material cost $=0.5 \sim 2 \%$, labor cost $=2 \sim 3 \%$ ), others (labor cost $=5 \sim 7 \%$ ), and general cost for assembling etc. (labor cost $=5 \sim 8 \%$ ). The installation cost is around $3 \sim 4 \%$ of construction cost. The operation and maintenance cost is dynamic and it increases with time. However, for implementation purpose a linear variation over the life cycle can be assumed, and at the design stage the operation and maintenance cost is assumed between 10 20\% of construction cost. Of late environmental regulations are getting tighter every year. This has affected the dismantling cost of semi-submersibles. At present, assuming a life cycle of 30 years, the dismantling cost of a semi-submersible is around $8 \sim 12.5 \%$ of construction cost.

Implementation of optimization approach: The parameters play an important role in the optimization and to gain a better insight into the design process it is desired that an optimization program is developed. The program allows a variation of the main design criteria, and helps in determining the effects of design criteria on overall size and shape of the semi-submersible. Initially, the design exercise starts with the market survey. The market survey coupled with the analysis by the design team helps in determining the main design criteria. Once, the main design criteria are determined then they are divided into owner's and shipyard's requirements.

We present the implementation details of an optimization program developed by us. In general the owner's requirements are: variable drilling load in operational, survival and transit condition (e.g. $\geq 5500$ tonnes), total variable load in transit condition including mooring spread (e.g. $\geq 10000$ tonnes), workability conditions in operations (e.g. up to $9 m$ significant waves and riser disconnection once every storm year), workability in survival condition (e.g. 100 years condition, maximum waves of $40 \mathrm{~m}$ height), classification societies (e.g. ABS/DNV/LRS etc.). The shipbuilding yard requirements are: optimizing parameter with respect to shipyard's constraints (e.g. shipbuilding yard's fabrication system, reduction of joints in the structure, and use plates of maximum size, etc.), maximum construction width (depends upon the available width of building dock, e.g. $\leq 80 \mathrm{~m}$ ), and minimize steel weight consumption. These requirements form the basic design set and from this set workability in operation and survival conditions are converted to the motional behavior input data (natural heave/pitch/roll period and second/third hump response). The significant wave height and storm conditions are combined with permissible strokes of the drill string compensator and the telescopic joint. The combination of these values computes the heave/pitch/roll motion curve in irregular seas. The experimental and analytical studies are used to determine the combination of natural period and response values at the second/third hump which satisfies the 
motion requirements. The height of air-gap is approximated to around $10 \sim 15 \mathrm{~m}$.

To clearly demonstrate the applicability of the presented optimization process we present a design example. Let the full set of input details for the conceptual design of a semisubmersible be: Free variables: $65 m<$ deck width $<80 m$. Due to available building dock width in the shipbuilding yard, $0 \mathrm{~m}$ $<$ column width, floater length, floater/column width, and floater height.

Parameters: $\quad \mathrm{VDL}=5500$ tonnes $, \quad \mathrm{TVL}=10,000$ tonnes, Height of air gap $=13 \mathrm{~m}$, Height of deck box $=10 \mathrm{~m}$, Number of bracings $=6$, and Diameter of bracings $=3.0 \mathrm{~m}$.

Constraints: GM operating $=4.50 \mathrm{~m}, \mathrm{GM}$ transient $=0.338 \mathrm{~m}$, Transient freeboard $=0.65 \mathrm{~m}$.

The results of the final optimized design are listed below: Rules and regulations ABS/DNV/LRS; Principal dimensions; $L$ of main deck=80.16m, $B$ of main deck $=71.15 \mathrm{~m}, D$ of main deck=48.38m, $D$ of flush bottom deck=39.38m, $L$ of lower hull $=133.85 \mathrm{~m}, B$ of lower hull $=15.475 \mathrm{~m}, D$ of lower hull $=10.25 \mathrm{~m}, \quad L$ of column $=15.475 \mathrm{~m}, \quad B$ of column $=15.475 \mathrm{~m}$, Longitudinal column space $=64.675 \mathrm{~m}$, Transverse space of column $=64.675 \mathrm{~m}, T$ of operation $=25.75 \mathrm{~m}, T$ of survival $=21.375 \mathrm{~m}, T$ of transit $=9.5625 \mathrm{~m}$; Capacities; Bulk mud and cement $=950 \mathrm{~m}^{3}$, Liquid $\mathrm{mud}=825 \mathrm{~m}^{3}$, Drill water $=2950 \mathrm{~m}^{3}$, Fuel oil $=3450 \mathrm{~m}^{3}$, Potable water $=500 \mathrm{~m}^{3}$, Ocean $/ \mathrm{sea}$ water $=500 \mathrm{~m}^{3}$, Sack storage $=213.45 \mathrm{~m}^{3}$, Drill pipe storage $=458.825 \mathrm{~m}^{3}$, Casing pipe storage $=376.25 \mathrm{~m}^{3}$, Riser storage $=706.367 \mathrm{~m}^{3}$; Variable load; Deck and column $=5500$ tonnes for operating $/$ survival $/$ transit condition, Lower hull=6750tonnes for operating/survival condition, Lower hull=2250tonnes for transit condition, Mooring=2500tonnes; Design criteria; Water depth $=1125 \mathrm{~m}$ for operating/survival condition, Wind $(60$ seconds $)=92 \mathrm{knots}$ for operating condition, Wind (60seconds) $=124 \mathrm{knots}$ for survival condition, Wind $(3600$ seconds $)=82 \mathrm{knots}$ for operating condition, Wind $(3600$ seconds $=110 \mathrm{knots}$ for survival condition, Significant wave height $/$ period $=10 \mathrm{~m} / 13$ seconds for operating condition, Significant wave height $/$ period $=23 \mathrm{~m} / 21$ seconds for survival condition, Maximum wave height $=19 \mathrm{~m}$ for operating condition, Maximum wave height $=43 \mathrm{~m}$ for survival condition, Surface current $=3.325 \mathrm{knots}$ for operating/survival condition, Temperature $=(-) 25^{\circ} \mathrm{C}$ for operating/survival condition; Machinery/equipment/out fittings; Anchors=11 21tonnes, Mooring lines $=12(100 \mathrm{~mm}$ diameter chain $\times 1275 \mathrm{~m}$ plus in length, $132 \mathrm{~mm}$ diameter wire $\times 2550 \mathrm{~m}$ plus in length), Cranes $=(3 \times 82.5)$ tonnes, Accommodation for 120 persons in 2 persons per cabin, Ballast pump room $=6$, Main generators $=6 \times 3500 \mathrm{~kW}$, and Azimuth thrusters $=4 \times 3125 \mathrm{~kW}$.

Some other designs that have been optimized with our program are listed in the Appendix.

The steel weight is roughly linearly dependent upon VDL. The operating conditions affect the design and though the reduction of maximum working conditions brings the second/third hump and period of heave/pitch/roll forward thereby reducing the steel weight but it increases the chances of riser disconnection. In proper design, these conflicting choices are settled with the preference given by the owner. Similarly, the drilling condition affects the steel weight. A higher value of drilling condition is preferred because it results in better earnings and additional cost of steel is low as compared to the enhanced earnings because of higher drilling condition. The owner's requirements strongly affect the final design, and parameters like VDL, TVL, GM all affect the steel weight, e.g. higher the VDL/TVL/GM higher the steel weight with TVL/VDL/GM being the order of decreasing influence on steel weight. The fabrication parameters like preference for flat panels, single curved panels, reducing number of main construction elements and continuous use of bulkheads from floaters to columns to upper hull result in significant cost savings (i.e. up to $20 \sim 30 \%$ of the cost of production of structure). The construction width affects the steel weight and final design. The optimum width balances the design with proper floaters, columns and deck dimensions within the set of input design data. The optimum ratio of $L / B$ for semi-submersibles is around 1.125 1.625.

Design is continuous and evolving process. The developments in one industry affect the design philosophies of other industries. For example, modularization has been implemented successfully in the aerospace industry, i.e. Boeing's series of 747,767 , and 787 , is a modular variation of basic Boeing's 747 design. We believe that offshore industry too can benefit from the concept of modularization and a similar modular approach can be taken for the design and construction of semi-submersibles.

Modularly, a semi-submersible can be viewed as a collection of pontoons organized in a central symmetric configuration. The modular configuration allows the deck and hull designs to be performed independently of each other resulting in a more efficient design process. Also, the construction schedules of deck and hull modules can be independent of each other and that allows maximization of efficiency in the scheduling process. Since, deck and hull modules are conceived independently any payload changes that can occur during the design process do not affect hull design/topsides design and the construction schedule. The configuration can be rectangular, square, hexagonal, and octagonal, etc.

The modular approach to the conception and design of deck and hull allow a robust and simple structural configuration, and a minimum of fatigue sensitive bracing connections can be achieved. The deck and hull can be connected rigidly or flexibly. The rigid and buoyant upper hull deck-box increases safety in an extreme event because of its extra strength and buoyancy. From stability point of view, the hull consists of the columns and the pontoons. The internal spaces of the columns are subdivided to provide access for shafts and a series of watertight flats. The pontoons can also be subdivided depending upon the requirements for damaged flotation and access. The vertical extent of the primary structure is designed to have a reserve buoyancy to prevent loss of the hull in occurrence of internal flooding during installation. The hull design uses 'crossstiffened' (i.e. $\times$ shaped) plating structures. The columns shape can be square or circular or elliptical design with ring girders and vertical stiffening. The pontoons can be rectangular or circular or elliptical design in cross section with web frames, and are stiffened in the longitudinal direction. The deck of the semi-submersible is installed at the 
quayside.

Normally, the deck comprises of two levels: cellar and production. The two levels are supported by the column structures. Also, modularization allows clean exterior surface of the hull with easy internal access for inspection, and this reduces the maintenance cost drastically and improves the life of the unit. The deck and hull can be enclosed with a 'deck-box' to protect equipment and systems to further reduce maintenance cost. The pontoons are centrally continuous and additionally columns are radially oriented towards outboard of the pontoon. The radial orientation of the columns improves the stability of the platform during quayside integration of the topsides, and therefore it minimizes the required displacement. Furthermore, since the pontoon structure is inboard of the columns, the requirements of compartmentalization are low and this allows the hull steel weight to be substantially low. The columns are connected and strengthened with a box girder system at the top. The topsides can be matched to column tops by simple lifting or float-over methods. The steel catenary riser or flexible riser can be supported inboard or outboard of the pontoon structure. Additionally, this configuration supports the conventional truss deck. The box girders improve the fatigue strength at the connections between the column and the deck as well as columns and pontoon. The box girder system sustains the pry and reduces the net effective loads. This structural configuration has many advantages: optimal displacement/payload ratio, optimal mooring design, less cost of construction, optimal stability, high fatigue lives for steel catenary risers, efficient deck structure, efficient design process, flexible design approach, and use of flat panel fabrication. The steel catenary riser porches can be used to support a variety of flow-lines. These porches can be located on the hull pontoons. The utility risers are distributed around the outside of the hull on the columns. The umbilicals are pulled up through and protected along the length of the hull by hawse pipes (I-tubes). The I-tubes extend from the base of the hull to the lower deck. This configuration forces the production and export riser interface to be under water on the lower hull. A fixed piping layout is provided from the export facilities on the deck, down the support structure, and down the outside of the main column to a flexible joint connector that is suspended from the steel catenary riser porch. The utility riser systems consist of seawater lift, firewater lift, and overboard drain lines. The production and drilling facilities need clear separation from the accommodation and utilities from safety point of view. A modular design offers that the operations of hook-up and assembly be performed at the quayside rather than offshore. The other benefits include ease for relocation and decommissioning, lower costs for hull and mooring equipment, better stability, and larger capacity for installation of risers.

Up to 1980 's, the oceans were treated like black holes that can absorb everything and anything dumped in them. However, since 1990's environmental concerns started making their presence known in the design of engineering structures. And, now the awareness of environmental problems is growing with each year, and laws and regulations governing design/operation/maintenance/dismantling of engineering structures are getting tighter. It is expected that by 2025 total intolerance of pollution and sustainability of the ecosystem will be implemented in design/operation /maintenance/dismantling of engineering structures. This will demand fundamental changes in the design process itself. To design efficient and environment friendly ships, the environmental considerations need to be superimposed on the basic semi-submersible design and construction, and the environmental systems are to be incorporated into mission/operational critical systems.

The idea is to develop new technologies and innovative designs of semis-submersibles to reduce fossil fuel based consumption, minimize $\mathrm{CO}_{2}, \mathrm{NO}_{\mathrm{x}}, \mathrm{SO}_{\mathrm{x}}$ emissions, and reduce the environmental impact caused by ballast water discharge. It is too early to predict what will be the future of technologies in the design of environment friendly semisubmersibles because research in this area is in its infancy. Still, we can list some areas that need proper investigations so that an efficient technology and design solution can be developed to address them. The areas are: Increasing deck/hull efficiency deck/hull optimization to improve semisubmersible performance in actual seas, reducing cavitation/bubble occurrence, using eco friendly hull coatings, reducing overall weight of the structure; Improving propulsion: efficient propeller design, improving propeller/hull interaction and propeller-rudder combinations, using diesel-electric propulsion; Increasing machinery efficiency: improving engine performance, efficient power management, saving energy, recovery of waste heat; Alternative propulsion methods: using fuel cell, solar, wave, wind, LNG, hydrogen; New design concepts: non-ballast semi-submersible, zero emission carrier semi-submersible; Operation performance: efficient weather routing, speed or trim optimization, Environmental impact: efficient ecological impact analysis from design to construction to dismantling, semi-submersible conversion and recycling; and International regulation: developing stricter codes and standards and implementing them.

\section{CONVERSION ISSUES FOR SEMI-SUBMERSIBLES}

In general, the offshore structures have high initial investment. So, even after the objective and life span for which an offshore structure was designed initially is over, it is preferred to convert it into another type of vessel. For example an offshore drilling semi-submersible can be converted into heavy-lift semi-submersible, crane semisubmersible, launching platform semi-submersible, and floating dry dock semi-submersible, floating production units, and dynamical positioned (DP) deepwater drilling unit, etc. Out of these options, conversion of offshore drilling semisubmersible into heavy-lift semi-submersible is technologically most complex and also requires heavy refitting and cost.

Also, the world semi-submersible fleet is growing old and current operational demand is based on equipment, systems, technical rules and regulations that are new. 
Furthermore, the requirements for deeper drilling depths and adverse weather conditions are bringing new challenges for the designers and operators. These new situations demand that the owners upgrade their existing units. In this scenario it is anticipated that many new opportunities are likely to open in the area of conversion/up-gradation of semi-submersibles.

Normally, the configuration of an offshore drilling semisubmersible is: one open controllable pitch propeller, lowspeed diesel engine, one/two transverse thruster at the bow, low width, and low deck area, etc. Now suppose this is to be converted to a heavy-lift semi-submersible. Normally, the configuration of a heavy-lift semi-submersible is: one open controllable pitch propeller, low-speed diesel engine, two/four transverse thruster at the bow, high width, and high deck area, etc. The high width and deck area of heavy-lift semi-submersibles allow the transportation of heavy structures (weighing up to 75000tonnes) and heavier and ultra-large floating production and drilling platforms and larger semi-submersible drilling units. The high width and higher displacement affects the propulsion, turning ability and safety adversely. From fundamentals of hydrodynamics it is known the requirements of higher propulsion, turning ability and safety can be achieved with addition of more thrust more so in adverse weather conditions. Hence, to obtain extra thrust new retractable thrusters can be installed at the bow. Also, the propeller can be upgraded, e.g. large nozzle (with curved outer profile and an inner profile that flares out to the trailing edge) with new propeller blades can be installed. A nozzle increases the thrust, and installation of a nozzle around the existing propeller increases the thrust without any additional requirement in the power of the engine. A nozzle needs to be installed in a tunnel, and then tunnel is covered within a box. Another option is to choose Pro-pac ${ }^{*} \mathrm{TM}$ rudder. This configuration allows the existing main engine, shaft-line and propeller to be used without any change. Any change in existing main engine, shaft-line and propeller hub is costly and therefore to be avoided.

Currently, new propeller designs are being researched. For example, to limit the tip speed of the propeller, a lower propeller diameter is preferred for heavy-lift semisubmersibles. A more detailed analysis is done to study the wake field at the aft of the ship, i.e. the wake field is important for propeller design because it determines the inflow of the propeller and therefore the cavitation behavior, hull pressure fluctuations and also the changes in thrust and torque during each revolution of the propeller blade. Additional thrust is provided by installing $2 / 4$ retractable thrusters at forward. The forward thruster is powered by a horizontal electric motor and the electric power is generated with generator sets.

\section{FUTURISTIC USES OF SEMI-SUBMERSIBLE}

As the world economies expand the energy demand continues to rise and this is pushing further the demands for inexpensive energy solutions. Since, available reservoirs of energy rich fossil fuels are slowly depleting major world economies are slowly shifting towards green energy. In this regard renewable energy options are being explored throughout the world at a faster pace as compared in the past.

Wind based energy is one of the most attractive option for renewable resources available to the planet earth. At present, most of the wind turbines are located at/near the coast at shallow and moderately deep waters. However, this is not very efficient because available wind speed is low at the coast and shallow depths. Low speed of wind generates low energy output and since the cost of installation of wind turbine farms is high the cost of energy per unit increases, making it uneconomical. To lower per unit cost of energy output, the energy generation needs to be increased. Fundamentally, the available speed of wind is high at deeper water depths and further away from coast. To explore this option we need to install offshore wind turbines. The wind turbines are installed on 'floating platforms' at few hundred kilometers out in to sea, where the winds are strong and steady. As has been mentioned previously because of their low motion characteristics semi-submersibles offer a stable floating platform at deeper water depths. At present, offshore wind turbines usually stand on 'fixed platforms' (e.g. towers driven into the ocean floor) which are suitable only up to water depths of about 15 20m. Installation of wind turbines on semi-submersible offers large space and efficient utilization of available wind speed. The semi-submersible mounted turbines can work in water depths ranging from 50 to $500 \mathrm{~m}$ or even more. And, more than one turbine can be installed on each semi-submersible and that can improve economy of scale in the wind farm. The assembling of floating turbine is expensive in open seas because height and size of wine turbine is high, e.g. height $=80 \sim 110 \mathrm{~m}$ and rotor diameter $=130 \sim 160 \mathrm{~m}$. So, it is better to assemble the units onshore at a shipbuilding yard and then tow out to sea by a tugboat. To keep the platform stable, cylinders inside it can be ballasted with concrete and water. Once on the site, the platform is installed and all the cylinders are de-ballasted. The installation of wind turbines on semi-submersible further demands that the motion be as low as possible and bottom of the turbine blades remain well above the peak of even the highest wave. This can be achieved with computer controlled dampers installed at the sideways. Because of the strong offshore winds, the floating turbines can produce up to thrice as much electricity per year (per installed megawatt) as wind turbines now in-practice. Additionally, since the floating wind turbines are not permanently attached to the ocean floor, they are a movable and that further allows maximization of energy generation as demanded by availability of high speed wind at an oceanographic location. With proper research and design, floating offshore wind turbines can be extrapolated to larger commercial scale embodiments convincingly.

Similarly, another use of semi-submersibles can be in tidal power plants. A tidal stream turbine can be installed on a semi-submersible for cost effective deployment in deep water tidal streams. At present, tidal stream turbine are installed at shallow water depths and they are of 'bottom cantilevered'. The 'bottom cantilevered' tidal stream turbine installation has high structural and installation costs, and difficulties of access for maintenance, at deeper water. And, 
most of resources are available only at deeper water. The semi-submersibles offer many advantages in the high-wave storm conditions and at deep water. With semi-submersible a turbine is installed on a buoyant structure suitable for deep water and a largely submerged configuration that avoids storm-force loads. The buoyancy features that support the structural configuration in the water can be controlled to rotate and lift the rotor and machinery parts out of the water into a position where they can be accessed easily for maintenance, and thereby reducing the energy consumption. This structural configuration allows the entire turbine and semi-submersible installation to be towed out to site for initial installation. To achieve maximum rate of return on investment, more research is needed to explore the accurate relationships between tidal stream and wind turbine technology so that the sizing of rotor blades, transmission design and structural support, and cost prediction is efficient. With proper research and design, semi-submersibles based tidal power plants can be extrapolated to larger commercial scale embodiments convincingly.

Table 3 An analysis of semi-submersibles for various depth ranges.

\begin{tabular}{|c|c|}
\hline S. No. & Semi-submersible \\
\hline $\begin{array}{c}\text { Deepwater range 1 } \\
(<2250 m)\end{array}$ & $\begin{array}{c}\text { Preferred because in this range } \\
\text { semi-submersibles are efficient } \\
\text { and economical. }\end{array}$ \\
\hline $\begin{array}{c}\text { Deepwater range 2 } \\
(2250 m \leq \mathrm{D}<3500 \mathrm{~m})\end{array}$ & $\begin{array}{c}\text { Preferred only when the storage } \\
\text { requirement is low, and offshore } \\
\text { platform is located close to the } \\
\text { onshore installations and operates } \\
\text { in a moderate weather. }\end{array}$ \\
\hline $\begin{array}{c}\text { Deepwater range 3 } \\
(\geq 3500 m)\end{array}$ & $\begin{array}{c}\text { In future very unlikely use for } \\
\text { this range. }\end{array}$ \\
\hline
\end{tabular}

\section{CONCLUSIONS}

This work has reviewed and reported the state of art on the challenges facing semi-submersible design. In our analysis we have shown that the design is an evolutionary process and the design of optimum choice for a chosen operating depth can only be done with a through and detailed analysis involving various options. We summarize our semisubmersible analysis in Table 3. This work has presented an analysis that can help in taking a more informed decision on an important issue in the offshore industry. The analysis reported in this paper can be further explored 'in-detail' to develop a comprehensive design manual that aid the design process for practicing engineers and academicians. Our future work shall go in this direction, and currently this is under investigation.

\section{ACKNOWLEDGEMENTS}

The first author was supported by the internal research grants of AICT, SNU, Republic of Korea for this work. Partially, this research was supported by the Korea Science and Engineering Foundation (KOSEF), Ministry of Education, Science and Technology (MEST), Government of Korea via grant number: 2009-0081219. The authors are thankful to Prof. R. P. Gokarn for his useful discussions with us that have contributed in increasing clarity of the present paper.

\section{REFERENCES}

ABS, 2001. Rules for building and classing steel vessels Part 4. ABS, USA, pp. 135-137.

API, 1996. Recommended Practice for Design and Analysis of Station-keeping Systems for Floating Structures. American Petroleum Institute, Second Edition, September 1996, USA, pp. 12-15.

API, 2003. Recommended practice for design, selection, operation and maintenance of marine drilling riser systems. American Petroleum Institute, API-RP-16Q, First Edition, November 2003, pp. 78-81.

CSSDCVB, 2009. Series of world records set in independence hub installation. Heerema Marine Contractors, www. hmc.heerema.com/Corp/News/20070417/.

DNV, 1996. Rules for classification of mobile offshore units. POSMOOR Booklet, version - Jan. 1996, pp. 35-45.

HMB, 2009. For immediate pick up - Stealth ship with housing barge - A Must See. GC Captain, www. gcaptain.com/.

KSC, 2009. Roll satellite launch from the Odyssey launch platform in the Pacific Ocean. NASA - Kennedy Space Center, www.ksc.nasa.gov/.

MVBM, 2009. MV Blue Martin. Maritime Quest, www.maritimequest.com.

NSS, 2009. Feds harpoon alleged 'Narco Submarine'. www.wired.com/threatlevel/2009/01/new-law-harpoon/.

Preston, A., 2001. The Royal Navy Submarine Service: A Centennial History. Conway Maritime Press, pp. 125129.

Sharma, R., Kim, T.W., and Sha, O.P., 2009a. Optimum conceptual design of an ultra-low motion semisubmersible floating oil and gas production system. In Proceedings of International Conference on Ship and Offshore Technology - India 2009, pp. 33-42.

Sharma, R., Kim, T.W., Sha, O.P., and Misra S.C., 2009 b. Semisubmersible design faces challenges. Offshore Marine Technology (OMT), $3^{\text {rd }}$ Quarter 2009, pp. 22 - 30.

Sharma, R., Misra, S.C., and Sha, O.P., 2009c. Deepwater drilling designs - System integration. Marine Engineers Review (MER), March 2009, pp. 41 - 44.

Sharma, R., Misra, S. C., and Sha, O. P, 2009d. Drillships or semi-submersibles for deep waters. Marine Engineers Review (MER), Feb. 2009, pp. 36 - 41.

SS, 2009. Sea shadow (IX-529). www.lockheedMartin.com.

TS, 2009. www.maritimesales.com/. 
TCSS, 2009. Construction gallery, SEMISUB Incorporated, USA. www.semisub1.com/gallery.shtml

USSD, 2009. USS Spuyten Duyvil 1864. www. americancivilwar.com.

\section{APPENDIX}

Detailed design example: MAIN DETAILS: HYN D 2500 DPUR; MAIN DESIGN: , $L=103.84 m$ (main hull excluding helideck), $B=74.15 \mathrm{~m}$ (main hull excluding anchor racks), $D=38 \mathrm{~m}$ (bottom line to upper hull main deck), $D=30.25 \mathrm{~m}$ (bottom line to flush bottom), Upper hull=7.75m deep ( $1.5 \mathrm{~m}$ inner bottom), Columns $=4 \times 21.46 \mathrm{~m}$ height, Pontoon level $=13.75 \mathrm{~m}$ square, Operating draft $=13.75 \mathrm{~m}$ (circular), Longitudinal spacing $=40.28 \mathrm{~m}(80.56 \mathrm{~m}$ overall $)$, Transverse spacing $=60.91 \mathrm{~m}$, Pontoons $=107.35 \mathrm{~m}(L) \times 13.75 \mathrm{~m}(B) \times 8.78 \mathrm{~m}(D) \quad$ (fore $/ \mathrm{aft}$ ); $46.83 m(L) \times 13.75 m(B) \times 8.78 m(D) \quad$ (port/stbd); DRAFT AND DISPLACEMENT: Operating draft $=19.75 \mathrm{~m}$, Transit draft $=8.25 \mathrm{~m}$, Survival draft $=14.82 \mathrm{~m}$, Operating displacement $=50031$ tonnes, Transit displacement $=35973$ tonnes, Survival displacement $=45416$ tonnes; OPERATING PARAMETERS: Water depth $=3000 \mathrm{~m}$, Maximum drilling depth $=9150 \mathrm{~m}$, Transit speed $=7 \mathrm{knots}$, Survival conditions - Wave $=27.45 \mathrm{~m}$, Wind $=105 \mathrm{knots}$, Current $=2.625 \mathrm{knots}$, Drilling conditions - Wave $=13.75 \mathrm{~m}$ ( 13 second), Wind $=55 \mathrm{knots}$, Current $=4.125 \mathrm{knots}$, Assisted mooring $=2 \times 5000 \mathrm{HP}$ thruster, Design conditions - Air temperature $=+38 \sim-20^{\circ} \mathrm{C}$, Water temperature $=+32 \sim-2^{\circ} \mathrm{C}$; MAIN MACHINERY: $6 \times$ diesel engines, $21000 \mathrm{~kW} / 28000 \mathrm{kVA}$ from 6 engine generators, Power distribution $=2$ main 6000 VAC buses, 480 VAC, 10 steel catenary risers, Emergency power $=800 \mathrm{~kW} / 1000 \mathrm{kVA}$ emergency generator, Propulsion $=2 \times 5000 \mathrm{HP}$ variable speed azimuthing thrusters; CAPACITIES: Variable drilling load=9225tonnes (operating), Variable drilling load=6150tonnes (transit), Riser rack area $=915 \mathrm{~m}^{2}$, Casing rack area $=472 \mathrm{~m}^{2}$, Other rack area $=1210 \mathrm{~m}^{2}$, Total rack area $=2597 \mathrm{~m}^{2}$, Free deck area $=1388 \mathrm{~m}^{2}$, Drill pipe in horizontal racker $=9150 \mathrm{~m}$, Sacks $=6000$ each, Drill water $=2650 \mathrm{~m}^{3}$, Potable water $=595 \mathrm{~m}^{3}$, Fuel oil $=2891 \mathrm{~m}^{3}$, Bulk amount of bentonite $=348.30 \mathrm{~m}^{3}$, Bulk amount of cement $=348.3 \mathrm{~m}^{3}$, Amount of liquid mud $/ \mathrm{salt}$ water $=3490 \mathrm{~m}^{3}$, Ballast water $=19690 \mathrm{~m}^{3}$; Drilling equipments: $52 \mathrm{~m} \times 20 \mathrm{~m} \times 13.45 \mathrm{~m}$ main hoist 1000tonnes and auxiliary hoist 350tonnes, Setblock=440tonnes (i.e., landing strings, casings, etc.), Drawworks $=4000 h p$, auxiliary $=1100 h p$, Rotary $=$ main and auxiliary $(16 m \times 1.6 m)$, Top drive $=$ main (775tonnes) and auxiliary (AC), Travelling block=main (1000tonnes) and auxiliary (350tonnes), Horizontal pipe handling $=12200 \mathrm{~m}$ (430 stands), Vertical pipe handling $=950 \mathrm{~m}$ (325 stands), Riser tensioners $=12$ mounts up to 3000kips capability, Motion compensator at main hoist (static=
1050 tonnes and dynamic $=525$ tonnes with $7.65 \mathrm{~m}$ stroke), Active Hv. Compensation installed; MUD SYSTEM: Cementing $=2 \times 600 h p$ (space availability $=2200 h p$ ), Mud pumps $=4 \times 2200 h p 52 M P a$, Mud processing equipment $=11425$ litres/minute (circulating rate), Desander $=3 \times 0.35 \mathrm{~m}$ cones, Desilter $=24 \times 0.15 \mathrm{~m}$ cones, Centrifuge= $4 \times$ decanting type and 2 additional, Shakers $=14 \times$ linear motion $(6$ scalpers, 6 finishing and 2 mud conditions), Pumps $=6 \times 8 \times 100 h p$, $10 \times 8 \times 100 h p$ (for mix processing) and $14 \times 8 \times 100 h p$ (for mud transferring), Hot swap mud system=yes; SUBSEA SYSTEMS: $\mathrm{BOP}=0.34 \mathrm{~m}(105 \mathrm{MPs}$, 5ram, 2annular, flexi joint and adapter), BOP handling system=transporter of 300tonnes, Control system $=$ multiplex hydraulic, Riser Details $=2500 \mathrm{~m}$, $0.575 \mathrm{~m}$ outside diameter and $27.50 \mathrm{~m}$ joint (buoyancy $=98 \%$ ), Telescopic joint $=16.825 \mathrm{~m}$ stroke, Diverter $=1.54 \mathrm{~m}$ inside diameter, Drill pipe $=$ outside diameters of $0.09 \mathrm{~m}, 0.128 \mathrm{~m}, 0.140 \mathrm{~m}$ and $0.170 \mathrm{~m}$, Drill collars $=$ outside diameters of $0.120 \mathrm{~m}, 0.165 \mathrm{~m}$, $0.210 \mathrm{~m}, 0.240 \mathrm{~m}$, TV system=ROV with $2500 \mathrm{~m}$ reach, Positioning=dynamic positioning system with lower flex joint angle, Choke and kill lines $=0.08 \mathrm{~m}$ inside diameter with $105 \mathrm{MPa}$ and trim compensation, Tree handling system=175tonnes transporter with skidding system and carts with maximum 6 trees in simultaneous operation, Subsea gantry $=100$ tonnes $\times 9 \mathrm{~m}$ span for BOP and 90tonnes $\times 11.4$ span for trees; MOONPOOL: $45 \mathrm{~m} \times 7.75 \mathrm{~m}$; CRANAGE: $3 \times 100$ tonnes $\times 55 \mathrm{~m}$ (boom range); MOORING SYSTEM: Winches $=12 \times$ traction winches, Wire $/$ chain $=12 \times 3100 \mathrm{~m} \times 0.09 \mathrm{~m}$ wire and $12 \times 1550 \mathrm{~m} \times 0.085 \mathrm{~m}$ chain, Anchors $=12 \times 15$ tonnes HHP, Thruster assisted mooring $=2 \times 5000$ tonnes $\mathrm{HP}$ thruster; Accommodation 160 people; DIVING SPEED=ROV installed in upper hull; ADDITIONAL INFORMATION: Motion characteristics=Heave period (20 25 seconds), Roll/pitch period (40 45 seconds), Life boats $=6 \times 54$ persons, Life rafts $=8 \times 20$ persons, Rescue boats $=1 \times 15$ persons and Fire fighting systems - helideck (aqueous filmforming foams (AFFF)), test areas (impreza inter-cooling water spray heat shield), Quarters (automatic fire sprinkling system), and Fire and gas detection (automatic fire and gas alarm systems).

Brief design example: MAIN DETAILS: HYN MD 1850 DP-UR; MAIN DESIGN: Water depth: 1850m, Oil throughput: 2.25 3.00 million tonnes per year, Gas throughput: 2 million cubic meters per day, Water throughput: 1.5 million tonnes per year, Number of production wells: 4 (sub-sea), Production risers: $6 \sim 8 \times 0.20 \mathrm{~m}$ steel catenary risers, Total payload (deck/facilities/risers) $=14500$ tonnes, Mooring=12 leg mooring system (with $0.23 \mathrm{~m}$ diameter polyester rope), Main hull dimensions: $\quad 70.5 m \times 70.5 m \times 51.75 m$, Main hull columns dimensions: $14 m \times 14 m$, Draft: $32 m$, Pontoon dimensions: $11.5 m \times 8 m$, Deck dimensions: $42.65 m \times 54.75 m$ and $42.65 m \times 12.25 m$ (in two levels). 